\title{
A Justiça na Igreja: compreensão teológico-jurídica
}

\section{The justice in the Church: theological-juridical understanding}

\section{Tarcísio Pedro Vieira ${ }^{1}$}

Resumo: A Igreja é por sua própria natureza promotora e defensora da Justiça. Para o cristão, promover a Justiça é realizar sua vocação: trabalhar pela salvação. No plano ético-religioso, a Igreja deve abrir-se à Justiça enquanto graça e dom de Deus, missão e compromisso, exigência da caridade e do reconhecimento da dignidade e dos direitos alheios. A Justiça, dessa forma, não será plena se não estiver vinculada diretamente à Caridade, à Misericórdia, à equidade, à paz e à verdade. A Igreja, embora considere o quanto preconizado pela filosofia e pelos juristas romanos, apresenta o conceito de Justiça enriquecido com o ensinamento bíblico-teológico, enfatizando a primazia da Caridade. A Caridade, por sua vez, tem sua expressão maior na Misericórdia. Assim, a razão de ser da Justiça Eclesial é a Misericórdia, considerando que a sua lei suprema é a salvação das almas.
Summary: The Church is by its very nature a promoter and defender of justice. For the Christian, to promote justice is to fulfill his vocation: to work for salvation. On the ethical-religious level, the Church must open itself to justice as a grace and gift of God, as a mission and commitment, as a demand for charity and for the recognition of the dignity and rights of others. The Justice, in this way, will not be full if it is not directly linked to Charity, Mercy, equity, peace and Truth. The Church, while considering what Roman philosophy and jurists advocated, presents the concept of justice enriched with biblical-theological teaching, emphasizing the primacy of Charity. Charity, in turn, has its highest expression in Mercy. Thus the raison d'être of Ecclesial Justice is Mercy, considering that its supreme law is the salvation of souls.

1 Bacharel, Mestre e Doutor em Direito Canônico pela Pontificia Universitas Lateranensis (Roma - Itália). Graduado em Teologia pelo Instituto Teológico de Santa Catarina (Florianópolis - Santa Catarina) / Centro de Estudos Superiores da Companhia de Jesus (Belo Horizonte - Minas Gerais) e em Filosofia pelo Centro Universitário de Brusque (Brusque - Santa Catarina). Diretor e Professor do Instituto Superior de Direito Canônico Santa Catarina. Professor da Faculdade Católica de Santa Catarina. Vigário Judicial do Tribunal Eclesiástico Regional de Florianópolis. 
Palavras-chaves: Justiça Eclesial. Caridade, Misericórdia e Justiça.
Keywords: Ecclesial Justice. Charity, Mercy and Justice.

\section{Introdução}

A Igreja é, conforme nos ensinou o Sínodo sobre a Justiça no Mundo, em 1971, ex natura sua promotora e defensora da Justiça: "Actio pro iustitia et participatio transformationis mundi plene nobis apparent tamquam ratio constitutiva praedicationis Evangelii, missionis nempe Ecclesiae circa generis humani redemptionem et liberationem ab omni statu oppresionis"2. O cristão, assim, ao promover a Justiça, realiza a sua vocação: trabalhar pela salvação. Ele deve, em primeiro lugar, buscar o Reino de Deus e a sua Justiça ${ }^{3}$. Como ensina a Constituição Gaudium et Spes: "Quicumque Christo obediens, primum quaerit Regnum Dei, inde validiorem ac puriorem amorem suscipit, ad omnes fratres suos adiuvandos et ad opus iustitiae, inspirante caritate, perficiendum"4.

Dessa maneira, a Igreja, sob o impulso do Espírito Santo, é chamada a trilhar o caminho da Justiça ${ }^{5}$, observando os ensinamentos do Senhor. Ao Senhor deverá sempre servir em Santidade e Justiça ${ }^{6}$. Enviada pelo mundo a pregar o Evangelho a toda criatura ${ }^{7}$, tem o dever de levar a todas as pessoas, indistintamente, Vida e Justiça. A Justiça é, assim, promessa do Reino de Deus ${ }^{8}$. A Igreja, edificada sobre

2 SYNODUS EPISCOPORUM. De iustitia in mundo. Acta Apostolicae Sedis, Vaticana, v. LXIII, n. 12, 22 dec. 1971. p. 924.

3 Mt 6,33.

4 CONCILIUM OECUMENICUM VATICANUM II. Constitutio Pasroralis Gaudium et Spes. Acta Apostolicae Sedis, Vaticana, v. LVIII, n. 15, 7 dec. 1966. p. 1094. Em português: "Todo aquele que, obedecendo a Cristo, procura em primeiro lugar o Reino de Deus, encontrará, em consequência, um amor mais forte e mais puro para ajudar todos os seus irmãos a realizar a obra da Justiça inspirada pela caridade" (CONCÍLIO VATICANO II. Constituição Pastoral Gaudium et Spes. In: VIER, F. (Coord.). Compêndio do Vaticano II: constituições, decretos, declarações. 23. ed. Petrópolis: Vozes, 1994. p. 229).

5 Mt 21,32 e 2Pd 2,21.

6 Lc 1,75 .

7 Mt 28,19 e Mc 16,5.

8 Mt 6,33. 
Cristo $^{9}$, único fundamento da Justiça ${ }^{10}$, é chamada a viver e anunciar a Justiça sempre e em toda parte ${ }^{11}$. A Justiça, então, será expressão concreta da Misericórdia de Deus e missão irrenunciável da Igreja.

No plano ético-religioso, a Igreja deve abrir-se à Justiça enquanto graça e dom de Deus, missão e compromisso, exigência da caridade e do reconhecimento da dignidade e dos direitos alheios. A Justiça, dessa forma, não será plena se não estiver vinculada diretamente à Caridade, à Misericórdia, à Equidade, à Paz e à Verdade.

\section{Referencial conceitual-filosófico de justiça}

O conceito denso e profundo de Justiça é suscetível a significados diversos segundo a ótica da reflexão ou da perspectiva que assume. A acepção ético-religiosa de Justiça tem suas raízes na filosofia grega. Muito cedo se delineou o conceito de Justiça como virtude universal. A escola pitagórica, por sua vez, apresentou uma acepção mais restrita e própria de Justiça enquanto medida nas relações intersubjetivas. Pitágoras, de fato, compreendia a Justiça essencialmente como igualdade $^{12}$. Mesmo não ignorando a noção pitagórica de Justiça, Platão tem um conceito próprio de Justiça, como nos ensina Del Vecchio:

[...] intendendo per giustizia quell'armonia che deriva dall'esplicazione delle attitudini spettanti alle varie parti dell'anima e alle varie classi sociali per il fine comune, che è la vita del tutto. Esigenza fondamentale della giustizia è pertanto

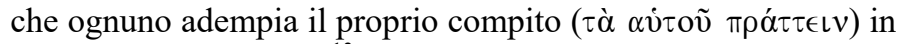
relazione a cotesto fine ${ }^{13}$.

Para Platão, a Justiça é concebida como virtude humana. Na perspectiva pessoal, a Justiça é a garantia da ordem na relação entre as três almas (concupiscível, irascível e racional), que constituem o ser

\footnotetext{
9 Ef 2,20-22 e 1 Cor 3,11.

101 Cor 1,30 .

11 Mc 16,15-20.

12 DEL VECCHIO, G. Giustizia. In: AZARA, A.; EULA, E. (Dir.) Novissimo Digesto Italiano. Torino: Torinese, 1961. v. VII. p. 1113.

13 DEL VECCHIO, 1961, p. 1113.
} 
humano. Na perspectiva social, a Justiça deve manter as classes sociais (governantes, guerreiros e artesões) na própria ordem, dando a cada classe o que é seu.

\begin{abstract}
Platone ripone l'essenza della giustizia nell'attuazione del pro-

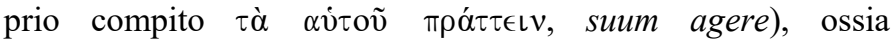
nell'esplicazione delle attitudini spettanti naturalmente ad ogni parte dell'anima e ad ogni ceto sociale. La giustizia così intesa, significa dunque la virtù che regge e armonizza l'operare tanto dei singoli, quanto delle moltitudini congregate, assegnando ad ogni facoltà od energia la propria direzione ed i propri uffici ${ }^{14}$.
\end{abstract}

Aristóteles, em sua Ethica Nicomachea, conjugando de um lado a teoria pitagórica e de outro a platônica, apresenta um conceito de Justiça que reúne em si, mas com precisa distinção, tanto o conceito geral de virtude total, ő $\lambda \eta \dot{\alpha} \rho \epsilon \tau \dot{\varepsilon}$ - no senso em que direciona a pessoa humana ao bem comum e se refere aos atos de todas as virtudes -, quanto o conceito mais específico e particular, $\tau \in \lambda \in i ́ \alpha$ - visando o bem privado.

O filósofo, aperfeiçoando o conceito de Justiça, precisou com maior clareza a Justiça particular, distinguindo-a em duas espécies: a distributiva e a comutativa. A Justiça distributiva é aquela que reparte os bens da comunidade com a devida proporção entre os cidadãos, cabendo ao Estado o ônus de dar a cada um o que lhe é devido. Na Justiça comutativa, por sua vez, o ônus cabe aos cidadãos nas relações recíprocas. Quando relaciona o direito à Justiça, considerando esta última enquanto virtude, Aristóteles mostra como "[...] la relazionalità intersoggettiva sia un alcunché di meta-naturalistico, come attenga, come nasca da un agire non casuale, né istintivo, ma intenzionale, meditato (e quindi, almeno in prospettiva, virtuoso) dell'uomo" $"$.

Para Aristóteles, a Justiça é “[...] la más importante de las virtudes y más admirable incluso que la estrella de la tarde y la de la ma-

14 DEL VECCHIO, G. Giustizia. In: CENTRO DI STUDI FILOSOFICI DI GALLARATE. Enciclopedia Filosofica. Venezia; Roma: Instituto per la Collaborazione Culturale, 1957.

15 D'AGOSTINO, F. Il diritto come problema teologico ed altri saggi di filosofia e teologia del diritto. In: ; VIOLA, F. (Dir.) Recta Ratio: testi e studi di filosofia del diritto. 3. ed. Torino: G. Giappichelli, 1997. p. 48. 
ñana. Y por esta misma razón empleamos de ordinario este proverbio: En la justicia se halla contenida toda otra virtud. La justicia es una virtud absolutamente completa $[\ldots]^{\prime \prime 16}$.

Retomado pelos romanos, o conceito aristotélico de Justiça assume um caráter jurídico mais preciso. Um exemplo clássico encontramos no Corpus Juris Civilis - Digestorum seu Pandectarum - De Iustitia et Iure, com Ulpiano: "Justitia est constans et perpetua voluntas jus suum cuique tribuendi"17. "Il suum che spetta a ciascuno è un complesso di diritti umani. Far valere la giustizia significa allora riconoscere e difendere i diritti di ogni persona"18. O direito é, assim, "l'occhio, il misuratore, la bilancia della giustizia", Como explicita G. Ghirlanda:

Lo ius suum, come contenuto della giustizia distributiva e di quella pareggiatrice o sinallagmatica (comutativa o giudiziaria), è il principio base del diritto naturale, che si radica nell'esigenza moral di associabilità dell'uomo, di essere cioè riconosciuto come soggetto, e di riconoscere com tale anche qualsisi altro uomo, con tutti i beni, valori e diritti propri ${ }^{20}$.

São Tomás acolhe, em harmoniosa fusão, o conceito de Justiça como virtude, próprio dos gregos, e a definição de direito, dos romanos - ou seja, o direito enquanto objeto da Justiça. Mesmo desenvolvendo o seu conceito num plano eminentemente ético-natural, São Tomás o enriquece e o completa com a dimensão e o significado bíblico-teológico de Justiça. Sua contribuição é baseada na "dottrina del

16 ARISTOTELES. Etica Nicomaquea. In: OBRAS. Madrid: Aguilar, 1964. p. 1227. Cf. ainda o comentário que São Tomás faz deste texto na Summa Theologiae, I-II, qu. 66, art. 4.

17 DIGESTA Iustiniani Augusti. Mediolani: Formis Societatis Librariae, 1960. I,1, fragm. 10. Em português: A justiça é a vontade constante e perpétua de dar a cada um o que é seu.

18 BONARA, A. Giustizia. In: ROSSANO, P.; RAVASI, G.; GIRLANDA, A. (Edd.). Nuovo Dizionario di Teologia Biblica. 3. ed. Milano: San Paolo, 1989. p. 714.

19 JEMOLO, A. C. Giustizia e Diritto. In: Ephemerides Iuris Canonici, 47, 1991. p. 36.

20 GHIRLANDA, G. Il Diritto nella Chiesa: mistero de comunione. In: COMPENDIO di Diritto Ecclesiale. 6 ed. Roma: Gregorian \& Biblical, 2015. p. 12. 
primato della carità cui la giustizia si rapporta e dalla correlazione mediatrice della legge naturale (in primo luogo della giustizia) con la legge di Cristo" 21 . O direito passa a ser, então, a força dinamizadora da Justiça.

Questa forza è dinamismo nel contempo morale e giuridico. Morale perché, come ogni virtù, come ogni atto cosciente e libero, anche la giustizia è espressione operativa del cuore dell'uomo, della sua opzione fondamentale di amore/carità, della sua personalità morale. Sia stato o no il diritto codificato e vincolato da una legge positiva, esso è sempre e primariamente un obbligo etico di coscienza. [...] Ma la forza dinamizzante del diritto è fonte anche di un obbligo giuridico o legale. La giustizia, a differenza delle altre virtù, induce ad agire anche sulla base di un titolo giuridico, riveniente dalla determinazione positiva e dalla codificazione legale del diritto ${ }^{22}$.

A partir do substrato conceitual aristotélico, São Tomás conceitua a Justiça como "habitus secundum quem aliquis constanti et perpetua voluntate ius suum unicuique tribuit",23. Ele considera a Justiça como virtude geral ${ }^{24}$, enquanto a lei ordena a atuação de todas as virtudes para o bem comum e inspira e regula a Justiça particular. A Justiça particular, por sua vez, ele a concebe como princípio de coordenação nas relações entre as pessoas. A Justiça particular é a Justiça do bem privado: "cum justitia ordinetur ad alterum, non est circa totam materiam virtutis moralis, sed solum circa exteriores actiones et res,

21 COZZOLI, M. Virtù Sociale. In: GOFFI, T.; PIANNA, G. (Cur.). Corso di Morale. 2 ed. Brescia: Queriniana, 2002. v. 4, Koinonia: etica della vita sociale. p. 61.

M. COZZOLI, 2002, p. 53.

23 Em português: "A Justiça é o hábito pelo qual, com vontade constante e perpétua, atribuímos a cada um o que lhe pertence." (THOMAS AQUINAS, Summa Theologiae. Trad. A. Corrêa. 2. ed. Porto Alegre: Sulina, 1980. II-II, qu. 58, art. 1).

24 São Tomás usa também a expressão de "justitia legalis", referindo-se ao ato exigido para o cumprimento de deveres sociais. A Justiça Legal ordena toda a comunidade ao bem comum (THOMAS AQUINAS, II-II, qu. 58, art. 6-7). 
secundum quamdam rationem objecti specialem, prout scilecet secundum eas unus homo alteri coordinatur" ${ }^{\prime 25}$.

Do momento em que a pessoa - ou um grupo particular, com personalidade moral - pode ser sujeito de direito na sua individualidade, autonomia e participação como membro de uma sociedade, a Justiça particular - de acordo com a distinção aristotélica ${ }^{26}$ - assume respectivamente duas formas: a comutativa e a distributiva, sendo que a primeira regula a justa relação entre as pessoas entre si, e a segunda regula a relação entre a sociedade e os seus membros.

Dessas considerações, é possível distinguir três elementos fundamentais do conceito de Justiça: a) a Justitia est ad alterum, entendendo a alteridade no seu sentido mais universal, ou seja, o outro enquanto simplesmente alter, antes de ser amigo, irmão, colega, companheiro, compatriota, etc., com toda a sua carga ontológica; b) a Justiça é criadora de uma ordem, mais precisamente da ordem da liberdade; c) e a Justiça é igualdade ${ }^{27}$. "Il ruolo della giustizia come valore-virtù relazionale e sociale sta propriamente nel perseguire e stabilire l'eguaglianza nella bilateralità delle parti, nella reciprocità del dirittodovere, nella parità dei soggetti, nella perequazione degli scopi" ${ }^{28}$. Ou, nas palavras do próprio São Tomás: "Ratio vero iustitiae consistit in hoc quod alteri reddatur quod ei debetur secundum aequalitatem"29.

A compreensão de Justiça, como foi possível sintetizar por meio desse lacônico referencial conceitual-filosófico, juntamente com a sua concepção evangélica - como se verá a seguir, fundamentam e deli-

25 Em português: "Por onde, a Justiça, ordenando-nos para outrem, não abrange toda a matéria da virtude moral, mas, só a que respeita as ações exteriores e as cousas, encarando-as no ponto de vista especial de fundarem as relações dos homens entre si." (THOMAS AQUINAS, II-II, qu. 58, art. 8).

26 ARISTOTELES, 1964, p. 1228-1229.

27 D'AGOSTINO, F. Filosofia del diritto. In: ; VIOLA, F. (Dir.). Recta Ratio: testi e studi di filosofia del diritto. 2. ed. Torino: G. Giappichelli, 1996. p. $17-20$.

28 COZZOLI, M., 2002, p. 54. Cf. ainda: S. THOMAS AQUINAS, 1980, II-II, qu. 57, art. 1.

29 Em português: “Ora, a Justiça, por natureza, consiste em dar a outrem o que lhe é devido, conforme a igualdade, como do sobredito se colhe." (THOMAS AQUINAS, 1980, II-II, qu. 80, art. 1.). 
neiam a ampla missão da Igreja como promotora e defensora de Justi$\mathrm{ça}^{30}$.

\section{A justiça na perspectiva cristã}

A Justiça, compreendida na perspectiva cristã, “[...] è la prima esigenza della carità quale riconoscimento della dignità e dei diritti del prossimo" "31. A originalidade e a tipicidade do significado bíblico e teológico da Justiça compreendem, superam e completam o significado filosófico-jurídico. Na compreensão evangélica, encontramos a interdependência substancial entre Justiça e Amor/Caridade ${ }^{32}$ :

[...] la giustizia si esplicita e dinamizza, nella sua inconfondibile originalità e singolarità, a partire dall'amore/carità, come via dell'amore/carità, in vista dell'amore/carità. In questa prospettiva, senza nulla perdere della sua tipicità, la giustizia vede ampliarsi il campo d'azione, avendo ritrovato una visione più personale, più etica, più dinamica e sociale del proprio oggetto: il diritto $^{33}$.

O Povo de Deus tem como lei maior - e, portanto, como expressão maior de Justiça - o amor: "Eu vos dou um novo mandamento: amai-vos uns aos outros. Como eu vos amei, assim também vós deveis amar-vos uns aos outros" ${ }^{\text {34 }}$. Desta feita, a dimensão da justiça em sen-

30 "La giustizia bíblica, sebbene differisca dalla nozione di giustizia elaborata dalla filosofia greca e ricevuta dalla giurisprudenza romana ("suum cuiuque tribuere"), tuttavia non l'esclude" (GHIRLANDA, 2015, p. 23).

31 BONARA, 1989, p. 714. Para um estudo mais aprofundado sobre a relação entre Justiça e Caridade, cf. a excelente obra PIZZORNI, R. Giustizia e Carità. Bologna: Il Mulino, 1995. Numa perspectiva jurídico-canônica, cf. BERLINGÒ, S. Dalla giustizia della carità alla carità della giustizia: rapporto tra giustizia, carità e diritto nella evoluzione della scienza giuridica laica e della canonistica contemporanea. In: COLLOQUIO INTERNAZIONALE ROMANISTICOCANONISTICO, VII. 1989. Vaticano. Atti...: Lex et Iustitia nell'utrumque ius radici antiche e prospettive attuali. Vaticano, Libreria Editrice Vaticana; Roma: Libreria Editrice Lateranense, 1989. p. 335-371.

33 COZZOLI, M. 2002, p. 76.

34 Jo 13,34 . 
tido estritamente jurídico, isto é, a Justiça enquanto direitos e deveres, deve abrir-se à uma perspectiva ainda mais elevada, isto é, a Justiça da santidade, que se funda na caridade. Assim, o princípio constitutivo da Justiça eclesial é a Caridade, que vem dar real significado e amplitude à Justiça do dar a cada qual o que é seu ${ }^{35}$.

O Reino de Deus é caracterizado pela concretização da Justiça e do Direito, sobretudo no que se refere à proteção da dignidade do mais fraco e pequeno. O Direito, assim, é objeto da Justiça. A função do direito positivo - apesar de seus limites - assume uma função divina, na medida em que é um meio para a instauração da Justiça de Deus entre a humanidade.

Na realidade, toda pessoa humana, a exemplo do Profeta Isaías, é vocacionada à Justiça: "Eu, o Senhor, te chamei para o serviço da Justiça!" 36 Os textos bíblicos cantam a Justiça como expressão concreta da misericórdia e da bondade de Deus. Ou, como afirma São Paulo: "Toda Escritura é inspirada por Deus e útil para instruir, para refutar, para corrigir, para educar na Justiça"37. A Justiça e o Direito pertencem a Deus: "Justiça e Direito são a base do teu trono, Amor e Verdade precedem a tua face" 38 . Justiça significa também Paz, isto é, integridade e plenitude de existência. Ambas são dons de Deus, inseparáveis uma da outra: "Justiça e Paz se abraçam"39. A Justiça, ainda, é expressão máxima de fidelidade à Lei do Senhor, enquanto instrução teórico-prática que visa à edificação da comunidade.

$\mathrm{Na}$ concepção veterotestamentária, a Justiça vem concebida, a título de síntese, com dois significados diferentes: de uma parte, indica uma atitude fiel, leal e construtiva no confronto da comunidade (e não obediência a uma norma ética ou jurídica) e, de outra, "[...] indica anche una condizione ottimale della comunità, uno stato di salute comunitario, per cui il singolo si trova a vivere entro una rete di relazioni pubbliche armoniose e salutar" 40 .

35 ERRÁZURIZ M., C. J. Il Diritto e la Giustizia nella Chiesa: per una teoria fondamentale del Diritto Canonico. Milano: Giuffrè, 2000. p. 124-125.

36

$2 \operatorname{Tm} 3,16$

38 S1 89,15.

39 S1 85,11.

40 BONARA, 1989, p. 714. 
A Justiça, desta forma, instaura, garante e mantém a comunhão. O justo é a pessoa solidária com os outros, capaz de edificar a comunidade. O responsável pela comunidade, por sua vez, deverá governar "exercendo o direito e fazendo Justiça a todo o povo"41. Concretamente, não há divisão entre a Justiça humana e a divina. A ação libertadora do Senhor em favor do seu Povo e a fidelidade do Povo em relação à Aliança ${ }^{42}$ são os elementos constituintes da relação de Justiça para o Povo de Israel: o Povo é justo na medida em que participa da Justiça de Deus.

La giustizia (sedeq/sedaqâ), in quanto indica le azioni di salvezza di Jhwh, è l'ambito divino nel quale l'uomo è posto, per grazia di Dio. La giustizia umana $\left(m^{i} s^{e} p a t\right)$ non si può separare da quella divina: per grazia, in quanto la giustizia divina è unita alla misericordia (Sal 33,5; 36,11; 40,11; 143,11), l'uomo è messo nell'ambito della giustizia di Dio, è salvato, e può agire secondo giustizia, perché fatto partecipe della giustizia e della misericordia di Dio (Prov 20,28; Is 165) ${ }^{43}$.

De fato, ainda que a Sagrada Escritura, ao referir-se constantemente à vontade transcendente e onipotente de Deus (em que a Justiça é vinculada intrinsecamente à Sabedoria, à Benignidade e à Misericórdia), dê à Justiça uma dimensão metafísica diferenciada, todavia, não exclui que a natureza histórica da Justiça de Deus se concretize através da regra do suum cuique tribuere, de modo que cada um seja acolhido como próximo do outro. Isso, contudo, não deve limitar a Justiça evangélica, que, por sua própria natureza, não consiste tanto em dar a cada um o suum, mas em "[...] riconoscere i bisogni più personali e fondamentali dell'altro"44. Isso porque o Amor/Caridade é a fonte, a alma e o coroamento da Justiça ${ }^{45}$. A Justiça, para a comunida-

\footnotetext{
$412 \operatorname{Sam} 8,15$.

42 Ex 20, Lv 19 e Dt 5. Sobre a dimensão teológico-jurídica da Aliança, cf. D'AGOSTINO, 1997, p. 56-59.

43 GHIRLANDA, 2015, p. 23.

44 HAMEL, E. I fondamenti dell'etica cristiana in ordine alla giustizia sociale: fede e giustizia sociale. In: Communio, Milano, 38, 1978. p. 75-76.

45 IOANNES PAULUS II. Littera Encyclica Dives in misericordia. Acta Apostolicae Sedis, Vaticana, v. LXXII, n. 9, 29 dec. 1980, p. 1200-1201, n. 7.
} 
de cristã, não pode se estabelecer no mero nível de valor e virtude, mas deve estar ordenada ao seu fim, como diz São Tomás: esta ordenação "est per caritatem" ". Dessa maneira, a Justiça, na concepção cristã, transcende a simples acepção do dar a cada um o seu ou do puro dar e receber, porque "[...] implica la compassione, la misericordia, la solidarietà, ossia, la fedeltà comunitária" ${ }^{47}$.

Dobbiamo allora riaffermare che giustizia e carità o diritto e amore sono i fondamenti morali di ogni vita sociale, che i valori morali sono indispensabili alla vita sociale, e che il diritto positivo dovrà tendere alla giustizia e portare la virtù, la pace $\mathrm{e}$ la felicità nell'unione e nell'amore fra gli uomini: opus iustitiae $\operatorname{pax}^{48}$.

A Justiça é mediação estrutural do Amor; é a primeira exigência e expressão de verificação e concretização da Caridade. Assim, "La giustitiza senza la carità diventa anonima, legalista, parziale. La carità senza giustizia diventa aleatoria, precaria, sentimentale. L'una senza l'altra rischia la svalutazione assiologica e il minismo etico. L'una con l'altra raggiunge il valore, la sollecitudine e l'incidenza massima"49. Por isso, urge a necessidade de dissipar todo equívoco de antinomia entre Justiça e Amor/Caridade.

Em Cristo, na Nova e Eterna Aliança, tem-se a realização plena da Justiça de Deus e o fundamento último para toda a Justiça humana. Com o Mistério Pascal de Cristo, é restituída ao ser humano a relação de Comunhão com Deus, com o próximo e com toda a natureza criada. A remissão do pecado reintegra o ser humano na sua dignidade de filho de Deus, como na parábola do filho pródigo (ou do pai misericordioso $)^{50}$ e faz com que a Justiça de Deus não apenas supere a Justiça legal humana, mas lhe seja fonte e inspiração. A Justiça de Deus,

46 Em português: "Ora, o bem último e principal do homem é o gozo de Deus, conforme a Escritura: Para mim é bom unir-me a Deus. E a isto o homem se ordena pela caridade.” (THOMAS AQUINAS, 1980, II-II, qu. 23, art. 7).

47 BONARA, 1989, p. 718.

48 PIZZORNI, 1995, p. 12-13, grifo do autor.

49 COZZOLI, 2002, p. 76.

50 Lc 15, 20-24. 
vivida e anunciada por Jesus, está a serviço da Vida e da dignidade da pessoa humana: "Eu vim para que tenham a vida"

De modo específico, as Bem-aventuranças ${ }^{52}$ exprimem a essência da Justiça evangélica, que vai identificada com a Caridade e com a Comunhão, que edificam a comunidade cristã. A Justiça do discípulo de Jesus deve superar a Justiça legalista dos escribas e fariseus ${ }^{53}$. A Justiça evangélica leva à perfeição e supera a Justiça puramente legal $^{54}$. Concretamente, ela exige mais que a simples observação exterior da lei, pois a sua dinâmica vem do interior e objetiva a caridade ${ }^{55}$; é fundamentada na atitude da conciliação e não se deixa ofuscar pelo egoísmo $^{56}$; supera a vingança - ius talionis ${ }^{57}$-, porque assegura, constrói e tutela a solidariedade e a comunhão na vivência da caridade fraterna ${ }^{58}$; expressa-se na sua mais profunda e sublime raiz, o amor pelos inimigos na busca da caridade perfeita ${ }^{59}$.

A Justiça evangélica, que brota do mistério da misericórdia divina, é fundamento e expressão das novas relações de amor e de liberdade, de comunhão e de paz. A Justiça é, então, a primeira exigência do Amor, ou como afirmou o Papa Paulo VI: "[...] la caridad no basta si se queda en pura teoría verbal y sentimental y no va acompañada de

Jo 10,10.
Mt 5,1-12.
Mt 5,20.
Mt 5,21-48.
Mt 5,21-24.
Mt 5,25-26.

A Lei de Talião, prescrita pelo Código de Hamurabi (século XX a.C.) era uma normativa comum a todos os povos do Oriente e que foi assimilada também pelo Código Mosaico (cf. Ex 21,24-25; Lv 24,17-21, Dt 19,21), permanecendo praticamente em vigor durante todo o Antigo Testamento (cf. Mt 5,38). Cf. ainda, para uma visão geral da Lei de Talião na Sagrada Escritura, o vocábulo talion na seguinte obra: PASSELECQ, G.; POSWICK, F. Table pastorale de la Bible: index analytique et analogique. Revue des Sciences Religieuses, Strasbourg, an. 50, n. 2, Avril 1976. p. 110.

58 Cf. Mt 5,38-42.

59 Cf. Mt 5,43-48. 
otras virtudes, la primera la justicia que es la medida mínima de la caridad $[\ldots]^{, 60}$.

Enquanto responsável pela promoção e defesa da Justiça no mundo $^{61}$, a Igreja tem o grande desafio de atuá-la na história, seja por meio do seu compromisso social (Justiça Social), seja através do exercício do seu munus iudicialis, ou seja, da atividade judiciária eclesial, na tutela e promoção da Justiça ao interno da comunidade eclesial e na defesa dos direitos/deveres legítimos dos seus membros ${ }^{62}$.

\subsection{A justiça social na Igreja}

A Justiça, na sua dimensão social ${ }^{63}$, ocupa um lugar preeminente na vida da Igreja, seja por meio do seu profético Ensinamento Social

60 PAOLO VI. Discorso per la Giornata dello Sviluppo: 1'amore di Cristo principio di rinnovamento morale e sociale. In: INSEGNAMENTI di Paolo VI. Vaticano: Typografia Poliglotta Vaticana, 1964. vol. VI. p. 384-385, grifo nosso.

61 Para uma visão completa da Justiça nos documentos do Concílio Vaticano II, cf. os vocábulos justicia e justicia social na seguinte obra: TORRES CALVO, A. Diccionario de los textos conciliares: Vaticano II. Madrid: COMPI, 1968. p. 1067-1073.

62 Não é objetivo deste estudo, nem pretensão nossa, entrar na questão polêmica sobre a compatibilidade ou não da dimensão jurídica do direito, seja na sua especificação histórica (normas canônicas), seja na sua própria essência (das Wesen der Recht) com a natureza da Igreja ou com a dimensão da graça e do amor evangélicos. Para uma visão geral sobre as questões levantadas pelo Protestantismo (Lutero, Karl Barth, Emil Brunner, J. Klein, etc.) e, especialmente, por Rudolph Sohm (jurista e teólogo, 1841-1918), bem como as reações às suas teses, cf. ERDÖ, P. Teologia del Diritto Canonico: un approccio storicoistituzionale. In: BERTOLINO, R. Collana di Studi di Diritto Canonico ed Ecclesiastico. Torino: Giappichelli, Torino, 1996. p. 12-13; CONGAR, Y. M.-J. R. Sohm nous interroge encore. Revue des Sciences Philosophiques et Théologiques, Paris, v. 57, n. 4, octobre 1973. p. 263-294, com excelente indicação bibliográfica entre as páginas 288-294; GHERRI, P. Lezioni di Teologia del Diritto Canonico. Vaticano: Lateran University Press, 2013.

63 Sobre a Justiça Social e a Doutrina Social da Igreja, dentre as inúmeras obras existentes nas diversas línguas, cf. PONTIFÍCIO CONSELHO JUSTIÇA E PAZ. Compêndio da doutrina social da Igreja. 7. ed. São Paulo: Paulinas, 2012; SPIAZZI, R. (Org.). I documenti sociali della Chiesa: da Pio IX a Giovanni Paolo II (1864-1982). Milano: Massimo, 1983; PONTIFICIO CONSIGLIO DELLA GIUSTIZIA E DELLA PACE. La dimensione sociale della fede oggi: Caritas in 
(Doutrina Social da Igreja) $^{64}$ - notadamente proclamado através das Encíclicas Sociais, de modo especial a partir de 1891, com a Encíclica Rerum novarum, do Papa Leão XIII, a Carta Magna da Doutrina Social da Igreja, até as últimas intervenções do Magistério -, seja por meio da sua concretização prática por meio da Pastoral Social.

A Justiça Social "[...] si tratta di quella specie di giustizia che si addice all'umanità in quanto famiglia dell'unico Dio. Trascendendo in maniera radicale la dimensione dell'interesse personale, essa si concentra sul bene comune" ${ }^{, 65}$. O bem-comum concretiza-se no conjunto daquelas condições da vida social que permitem aos grupos e a cada um de seus membros atingirem, de maneira mais completa e desembaraçadamente, a própria perfeição. A Doutrina Social da Igreja é expressão singular da profunda sensibilidade pastoral da Igreja diante da complexa e dinâmica realidade socioeconômica hodierna; é expressão da missão que Cristo confiou à Igreja em favor da pessoa humana. A Justiça é sinal de viva esperança e certeza de vida nova: “[...] sed docemur Deum novam habitationem novamque terram parare in qua iustitia habitat, et cuius beatitudo omnia pacis desideria, quae in cordibus hominum ascendunt, implebit ac superabit" ${ }^{\prime 66}$.

No Documento do Sínodo dos Bispos de 1971, reafirma-se a missão da Igreja na defesa e promoção da vida, da dignidade e dos di-

veritate e Evangelii gaudium. Vaticano: Libreria Editrice Vaticana, 2015; DE SIQUEIRA, J. C. Laudato Sí: um presente para o planeta. Rio de Janeiro : PUC, 2016.

64 A Doutrina Social da Igreja, segundo Mauro Cozzoli, "È un insegnamento universale-umano che indirizza e vincola le coscienze in nome dell'uomo, del suo valore, della sua dignità. In questo la Chiesa ha la consapevolezza di svolgere non un compito secolare o profano, aggiuntivo o di supplenza etico-sociale nel mondo, ma di adempiere il ministero salvifico suo proprio che trova nel servizio della verità dell'uomo - espressione della sapienza creatrice di Dio - un momento essenziale e ineludibile della sua missione evangelizzatrice" (COZZOLI, M. Il settimo comandamento. In: FISICHELLA, R. (Cur.). Commento Teologico al Catechismo della Chiesa Cattolica. Casalle Monferrato: PIEMME, 1993. p. 579. HÄRING, B. Liberi e Fedeli in Cristo: teologia morale per preti e laici. 2. ed., Roma: San Paolo, 1982. v. III. p. 345.

66 CONCILIUM OECUMENICUM VATICANUM II, 1966, p. 1056-1057. Em português: "[...] Deus prepara morada nova e nova terra. Nela habita a Justiça e sua felicidade será satisfazer e superar todos os desejos da paz que sobem nos corações dos homens. (VIER, 1994, p. 182). 
reitos da pessoa humana - em todos os sentidos -, como consequência da relação intrínseca e necessária entre Amor e Justiça:

L'amore cristiano del prossimo e la giustizia non possono essere separate tra loro. L'amore, infatti, implica un'assoluta esigenza di giustizia, ossia il riconoscimento della dignità e dei diritti del prossimo; la giustizia, a sua volta, raggiunge la sua interiore pienezza unicamente nell'amore. E poiché ogni uomo è in realtà immagine visibile dell'invisibile Dio e fratello di Cristo, appunto per questo il cristiano trova in ogni uomo Dio stesso e quell'assoluta esigenza di giustizia e di amore, che è propria di $\mathrm{Dio}^{67}$.

O Beato Papa Paulo VI, na Exortação Apostólica Evangelii nuntiandi, proclama que a evangelização não seria completa se não considerasse a recíproca interpelação que se fazem constantemente o Evangelho e a vida concreta, pessoal e social do ser humano ${ }^{68}$. Desta forma, a evangelização comporta uma mensagem explícita, adaptada às diversas situações e constantemente atualizada sobre os direitos e deveres de cada pessoa humana à vida familiar, vida internacional, paz, Justiça, desenvolvimento, enfim, uma mensagem vigorosa sobre a libertação. Anunciar e testemunhar a Libertação total, através da Justiça, é missão da Igreja.

São João Paulo II, em diversas ocasiões, exalta e interpela a Igreja a assumir essa sua especial missão. Adquire um valor relevante o memorável discurso inaugural da III Conferência Geral do Episco-

67 SINODO DEI VESCOVI. De iustitia in mundo. In: LORA, E. (Cur.). Enchiridion Vaticanum. 13. ed. Bologna: EDB, 1985. p. 817. Original latino: SYNODUS EPISCOPORUM, 1971, p. 935.

68 PAULUS VI. Adhortatio Apostolica Evangelii nuntiandi. Acta Apostolicae Sedis, Vaticana, v. LXVIII, n. 1, 31 ian. 1976. p. 25. Em português: Mas a evangelização não seria completa se ela não tomasse em consideração a interpelação recíproca que se fazem constantemente o Evangelho e a vida concreta, pessoal e social, dos homens. E por isso que a evangelização comporta uma mensagem explícita, adaptada às diversas situações e continuamente atualizada: sobre os direitos e deveres de toda a pessoa humana e sobre a vida familiar, sem a qual o desabrochamento pessoal quase não é possível, sobre a vida em comum na sociedade; sobre a vida internacional, a paz, a justiça e o desenvolvimento; uma mensagem sobremaneira vigorosa nos nossos dias, ainda, sobre a libertação. 
pado Latino-americano, em Puebla ${ }^{69}$, onde o Papa asseverou que a Igreja, fiel ao Evangelho, tem consciência de que a sua missão possui como parte indispensável a ação pela Justiça e as tarefas de promoção do homem, e que entre evangelização e promoção humana existem laços bem fortes de ordem antropológica, teológica e de caridade.

O Código de Direito Canônico de 1983, por sua vez, prescreve, a todos os fiéis, o dever de promover a Justiça social e de socorrer os pobres com as próprias rendas: "Obligatione quoque tenentur iustitiam socialem promovendi necnon, praecepti Domini menores, ex propriis reditibus pauperibus subveniendi" ${ }^{70}$. Não é possível viver o compromisso coerente de fé sem que ela se expresse na caridade e na Justiça.

\subsection{A potestas iudicialis}

Da sua dimensão comunitário-institucional ${ }^{71}$, nasce, na Igreja, a necessidade de uma organização judicial que garanta a Justiça ao seu interno e defenda o interesse legítimo dos seus membros, como expressão da verdadeira comunhão e da vivência do amor evangélico. Assim, o ordenamento jurídico-eclesial ${ }^{72}$ - e a sua respectiva normati-

${ }^{69}$ CONFERÊNCIA GERAL DO EPISCOPADO LATINO-AMERICANO. Evangelização no presente e no futuro da América-Latina: conclusões da III Conferência Geral do Episcopado Latino-Americano. 5 ed. São Paulo: Paulinas, 1983.

CODEX Iuris Canonici. Acta Apostolicae Sedis, Vaticana, v. LXXV, pars II, 1983. c. $222, \S 2$.

71 "Gli uomini, per la loro natura sociale, costituiscono non un semplice aggregato di individui, ma una comunità di persone nella quale i bisogni e le aspirazioni di ciascuno, gli eguali diritti e i simmetrici doveri, si collegano e si coordinano in un vincolo solidale, ordinato a promuovere il pieno sviluppo della persona umana e la costruzione del bene comune. Ciò implica l'affermazione di regole di condotta, connaturate al concetto medesimo di società, che non soltanto rispecchiano giudizi di valore universalmente riconosciuti, ma presiedono al corretto svolgimento dei concreti rapporti tra gli uomni, equilibrando le individuali libertà e orientandole verso la giustizia. Senza tali regole, una società libera e giusta non può consistere" (BERTONE, T. La Chiesa e l'impegno per la giustizia. Legalità, giustizia, moralità. In: LA GUISTIZIA nella Chiesa: fondamento divino e cultura processualistica moderna. Vaticano: Libreria Editrice Vaticana, 1997. p. $8)$.

72 "[...] l'ordinamento canonico si specifica per essere universale ordinamento di iustitia maior, di quella superiore giustizia, cioè, (la carità) che, mentre quella 
va (direito canônico ou eclesial) - não aparece somente como uma norma de vida ou regra pastoral, mas também como "scuola di giustizia, di discrezione e di carità operante" ${ }^{, 73}$.

A autoridade judiciária é, de fato, uma autoridade de serviço; um serviço que consiste no exercício do poder confiado por Cristo à sua Igreja para o bem de todos, ou seja, para a realização da salus animarum. Torna-se assim uma exigência que a própria Comunidade Eclesial seja, ela mesma, um locus iustitiae, isto é, que saiba "[...] realizzare questo valore al proprio interno, sia nel pieno riconoscimento della dignità e della libertà delle persone, sia nei rapporti fra le varie componenti del popolo di Dio [...]"74.

A Igreja, Corpo Místico de Cristo ${ }^{75}$, na dinâmica de sua existência enquanto Sociedade sui generis ${ }^{76}$, vive na história e não pode prescindir de uma organização jurídico-social ${ }^{77}$ que coordene os seus membros na busca do seu fim: a salus animarum ${ }^{78}$. De fato, a Igreja, Societas caritatis $^{79}$, tem a missão de ser instrumento de salvação e, desta forma, a administração da Justiça não assume outra meta senão a de estar a serviço da Missão da Igreja. Com isso, evidencia-se que o objetivo do ordenamento jurídico-canônico e das leis eclesiais não é, de forma alguma, substituir, na vida da Igreja ou dos fiéis, a fé, a graça, os carismas, nem muito menos a Caridade. Pelo contrário, sua fi-

giuridica fa dire agli uomini fiat iustitia, pereat mundus, fa dire ai cristiani fiat iustitia ut salvetur mundus!" (LENER, S. Sulla natura specifica del Diritto Canonico. La Civiltà Cattolica, Roma, v. 133, n. 3, 1982. p. 235).

73 PAULUS VI. Allocutiones: VII ad Praelatos Auditores et Officiales Tribunalis Sacrae Romanae Rotae, a Beatissimo Patre novo litibus iudicandis ineunte anno coram admissos. Acta Apostolicae Sedis, Vaticana, v. LXV, n. 2, 28 feb. 1973. p. 95.

74 CAMPANINI, G. Giustizia. In: PACOMIO, L. (Coord.). Dizionario Teologico Interdisciplinare. Torino: Marietti, 1977. v. 2. p. 255.

76 A natureza racional, social e associativa do ser humano, como propõe o axioma ciceroniano: "ubi societas ibi ius", permite de conceber a organização jurídicoestrutural da Igreja, a partir da dimensão social da pessoa humana.

77 Sobre a dimensão visível e jurídica da Igreja, cf. ARROBA CONDE, J. M. La Iglesia como presencia. Vida Religiosa, v. 86, n. 3, 1999. p. 183-192.

78 CÓDIGO, 1983, c. 1752.

78 CÓDIGO, 1983, c. 1752.

79 R. PIZZORNI, 1995, p. 387. 
nalidade é, antes de tudo, criar na sociedade eclesial uma ordem que, dando primazia ao amor, à graça e aos carismas, facilite, ao mesmo tempo, seu desenvolvimento orgânico-institucional.

Dessa maneira, o direito eclesial, enquanto regulador das relações da Igreja (internas e externas) e como expressão do seu ordenamento jurídico-institucional, não é um fim em si mesmo, mas uma forma especial de serviço da Justiça e da Caridade. Os ensinamentos do Papa São Leão Magno (fim do século IV) ajudam a recordar que amar a Deus e amar a Justiça constituem um único mandamento: "Nihil aliud est diligere Deum quam amare iustitiam"

Os fiéis cristãos, no seio da própria Igreja, têm o direito de reivindicar e defender legitimamente os direitos de que gozam na Igreja, no foro eclesiástico competente, e, ao mesmo tempo, se chamados a juízo, têm o direito de serem julgados de acordo com as prescrições do direito, a serem aplicadas com equidade ${ }^{81}$. Desta forma, a função judicial da Igreja está a serviço da comunhão, baseada no controle da legitimidade e da aplicação da Justiça às situações controversas no seio da própria comunidade eclesial e no interesse legítimo dos próprios membros.

Nessa perspectiva, a tutela dos direitos dos fiéis cristãos é conexa diretamente ao respeito fundamental dos direitos humanos, enquanto reconhecimento da dignidade da pessoa humana, que, na teologia cristã, à luz da revelação divina, assume uma grande riqueza doutrinal e uma dimensão transcendente. "Vana sarebbe la proclamazione dei diritti dei fedeli nella Chiesa se non ci fosse la possibilità di un'adeguata difesa di tali diritti”, ${ }^{\circ 2}$. A defesa destes direitos está na base da função judicial da Igreja.

80 LEO MAGNUS. Sermo XCV: sive homilia de gradibus ascensionis ad beatitudinem. In: MIGNE, J. P. (Cur.). Patrologiae cursus completus. Paris: 1844-1866. Series Latina, tom. LIV. p. 464.

81 CODEX, 1983, c. $221, \S 1-2$ e c. $1400, \S 1$.

82 GROCHOLEWSKI, Z. Aspetti teologici dell'attività giudiziaria della Chiesa. Monitor Ecclesiasticus, Roma, 110, 1985. p. 492. 


\section{Justiça, caridade e misericórdia}

É mister, porém, recordar que a Justiça deve estar sempre em harmonia com a misericórdia e a caridade ${ }^{83}$, como já enunciava $o$ Mestre Graciano: "Iuste iudicans misericordiam cum iustitia servat" 84 , no senso que a misericórdia e o perdão não contradizem a Justiça e nem a negam, mas a transcendem, como esclarece São Tomás: "Ex quo patet quo misericordia non tollit iustitiam sed est quaedam iustitiae plenitudo" ${ }^{85}$.

$\mathrm{O}$ ordenamento jurídico-eclesial, com seus respectivos institutos jurídicos, tem sua fundamentação primordial e justificativa primeira na natureza racional da pessoa humana e na sua dimensão relacional. A racionalidade humana, por sua vez, está na base dos atos humanos, enquanto estes devem ser atos livres, conscientes e desejados. Na realidade, o ser humano enquanto aspira à liberdade, descobre-se um ser relacional, porque não vive e não pode existir sozinho. A pessoa humana é destinada à "con-vivência", à "com-unidade", a "ser-com-osoutros". E isso requer respeito à alteridade e à recíproca liberdade e colaboração comum; é necessário falar de fraternidade/sororidade universal. ${ }^{86}$

Dessa forma, torna-se necessário instaurar uma ordem social, com princípios éticos e jurídicos, que regule as relações intersubjetivas, a fim de garantir, sincronicamente, uma fraterna e justa convivência social (bem social) e a plena realização de cada membro na comunidade (crescimento e bem-estar individual de cada pessoa humana). Aplicando tais princípios da teoria geral do direito à Comunidade Eclesial, é

83 LENER, S. Giustizia, carità e misericordia: per un'analisi correlativa delle tre idee. La Civiltà Cattolica, Roma, v. 132, n. 2, 1981. p. 338-357.

84 DECRETUM Magistri Gratiani. London: Forgotten Book, 2018. pars 1, dist. 45, can. 10.

85 THOMAS AQUINAS, 1980, I, qu. 21, art. 3. Em português: "Donde resulta que, longe de suprimir a Justiça, a misericórdia é a plenitude dela."

86 VIEIRA, T. P. O nosso Deus, um Deus Ecológico: por uma compreensão éticoteológica da ecologia. São Paulo: Paulus, 1999. p. 74-76. 
necessário ter presente que "la Iglesia es siempre institución, pero es más que eso" ${ }^{\$ 7}$ e o ordenamento jurídico-eclesial tem como escopo

promuovere la personale vocazione dei fedeli e di articolare i beni tipici della comunità ecclesiale, relativi alla partecipazione alla sua vita e missione; da ciò deriva un insieme di diritti ed obblighi fondamentali per tutti i fedeli, in una posizione di uguaglianza derivata dal battesimo, sebbene differenziati a seconda del ruolo svolto nella comunità ecclesiale ${ }^{88}$.

Assim, o ordenamento jurídico-eclesial na sua função unitiva, mais que um instrumento de controle - com suas notas específicas: imperatividade, certeza e coercibilidade, que garantem a eficácia da lei -, é uma realidade que deve ser controlada, ou seja, "susceptible de cambio, de la evolución y de la reforma. [...] Las instituciones de la iglesia pueden y deben ser criticadas en orden a su mayor eficacia apostólica, a sua adaptación a la sociedad y a los tiempos, y a su mayor coherencia evangélica",89.

Para isso, a Igreja deverá fazer reinar sempre a Caritas, enquanto mandatum novum do Senhor, seja, como vimos, na ordem social, seja na dinâmica interna da sua vida eclesial. O ordenamento jurídicoeclesial estará, assim, diretamente vinculado à realidade mais profunda da pessoa humana, isto é, à sua relação com Deus e com o mistério da redenção.

No mistério da redenção, todavia, a Justiça tem razão de ser na Misericórdia, que é expressão essencial da Caridade. A Misericórdia é a mais bela manifestação do Amor que Deus por nós. Para tanto, é assaz significativo, ainda vivendo das graças obtidas no Jubileu Extraordinário da Misericórdia, recordar o quanto o Papa Francisco assevera a cerca da relação intrínseca e interdependente entre Justiça e Misericórdia, apontando, no entanto, a primazia da Misericórdia, enquanto expressão máxima do amor.

87 ESTRADA, J. A. La Iglesia ¿Institución o carisma? Salamanca: Sigueme, 1984. p. 172.

88 ARROBA CONDE, M. J. Diritto processuale canonico. 6 ed. Roma: Ediurcla, 2012. p. 19.

89 ESTRADA, 1984, p. 171. 
Nesse contexto, a Misericórdia Evangélica vem a ser luz que ilumina e dá um sentido ulterior à Justiça Eclesial ${ }^{90}$. São Tomás já havia dito que a Misericórdia não elimina a Justiça, mas é o seu coroamento e plenitude ${ }^{91}$. São Tiago também nos recorda que a "misericórdia triunfa sobre o julgamento" 92 . Diz, ainda, São Tomás, que "Opus autem divinae iustitiae semper praesupponit opus misericordiae, et in eo fundatur"93. A propósito, é bom recordar o que já dizia o Decretum Magistri Gratiani: "Disciplina non est servanda sine misericordia, nec misericordia sine disciplina [...] Disciplina vel misericordia multum destituitur, si una sine altera teneatur $[\ldots]$..."

$\mathrm{Na}$ verdade, a misericórdia humana tem sua fonte na Misericórdia Divina. A Misericórdia é a palavra-chave de toda a história da Salvação, porque Cristo é "la misericordia incarnata di Dio"95. Jesus veio para trazer a Misericórdia, como diz a Epístola aos Efésios ${ }^{96}$. E a Igreja, em todas as suas dimensões, mas, especialmente, no seu ministério de Justiça, deve professar e proclamar a misericórdia de Deus, tornando-a realidade, atuando-a através de seu testemunho e da vivência do amor.

A Igreja deve considerar como um de seus principais deveres a proclamação e a concretização do mistério da Misericórdia. Por isso, não basta somente a Justiça em si mesma. A aplicação rígida da lei, a atuação de uma Justiça sem a medida da caridade e da misericórdia pode tornar-se fonte de injustiça, como adverte Cícero: "summum ius,

90 PIZZORNI, 1995, p. 373-384

91 THOMAS AQUINAS, 1980, I, qu. 21, art. 3.

$92 \operatorname{Tg} 2,13$.

93 THOMAS AQUINAS, 1980, I, qu. 21, art. 4. Em português: "Mas a obra da divina Justiça sempre pressupõe a da misericórdia e nesta se funda."

94 DECRETUM, 2018, pars 1, dist. 45, can. 9.

95 PIVA, P. Misericordia. In: ROSSI, L.; VALSECCHI, A. (Dir.). Dizionario Enciclopedico di Teologia Morale. 7 ed. Milano: Paoline, 1987. p. 664.

96 Ef 2,4-7: "Mas Deus, que é rico em misericórdia, pelo grande amor com que nos amou, quando estávamos mortos em nossos delitos, nos vivificou juntamente com Cristo - pela graça fostes salvos! -, e com ele nos ressuscitou e nos fez assentar nos céus, em Cristo Jesus, a fim de mostrar nos tempos vindouros a extraordinária riqueza da sua graça, pela sua bondade para conosco, em Cristo Jesus." 
summa iniuria"97. A misericórdia deverá acompanhar cada um dos atos de Justiça na Igreja. É ela quem concede à Justiça uma cordial ternura e sensibilidade, tornando-a verdadeiro instrumento de salvação. Na verdade, "misericordia vera altissimus est iustitiae fons" "98.

São João Paulo II, na mensagem para a Celebração do XXXV dia Mundial da Paz, ressaltou de forma muito enfática a importância fundamental da relação entre perdão, Justiça e paz, asseverando que não há paz sem Justiça e não há Justiça sem perdão ${ }^{99}$. Anos mais tarde, Papa Francisco, na Bula de abertura do Ano Jubilar Extraordinário da Misericórdia, ajuda a compreender tal relação, quando diz que a Justiça e a Misericórdia "non sono due aspetti in contrasto tra di loro, ma due dimensioni di un'unica realtà che si sviluppa progressivamente fino a raggiungere il suo apice nella pienezza dell'amore" ${ }^{\text {"100. }}$. Prossegue o Papa:

La giustizia è un concetto fondamentale per la società civile quando, normalmente, si fa riferimento a un ordine giuridico attraverso il quale si applica la legge. Per giustizia si intende anche che a ciascuno deve essere dato ciò che gli è dovuto. Nella Bibbia, molte volte si fa riferimento alla giustizia divina e a Dio come giudice. La si intende di solito come l'osservanza integrale della Legge e il comportamento di ogni buon israelita conforme ai comandamenti dati da Dio. Questa visione, tuttavia, ha portato non poche volte a cadere nel legalismo, mistificando il senso originario e oscurando il valore profondo che la giustizia possiede. Per superare la prospettiva legalista, biso-

97 "Exsistunt etiam saepe iniuriae calumnia quadam et nimis callida sed malitiosa iuris interpretatione. Ex quo illud Summum ius summa iniuria factum est iam tritum semone prouerbium." Tradução em francês : "Il se trouve souvent aussi des injustices du fait d'un certain abus de la loi et d'une interprétation extrêmement habile mais trompeuse du droit. C'est pourquoi l'adage summum ius, summa iniuria: la limite extrême du droit, c'est le comble de l'injustice, est devenu un proverbe passé dans l'usage" (CICÉRON. Le Devoir. Étab. et trad. M. Testard. 2. ed. Paris, 1974. p. 120, X-33.).

IOANNES PAULUS, 1980, p. 1223.

GIOVANNI PAOLO II. Non c'è pace senza giustizia, non c'è giustizia senza perdono: messaggio di Sua Santità Giovanni Paolo II per la Giornata Mondiale della Pace. L'Osservatore Romano, Vaticano, CXLI, n. 284, 12 dic. 2001.

100 FRANCISCUS. Bulla de Iubilaeo Extraordinario indicendo Misericordiae Vultus. Acta Apostolicae Sedis, Vaticana, v. CVII, n. 5, 1 maii 2015. p. 414. 
gnerebbe ricordare che nella Sacra Scrittura la giustizia è concepita essenzialmente come un abbandonarsi fiducioso alla volontà di Dio. [...] La misericordia non è contraria alla giustizia ma esprime il comportamento di Dio verso il peccatore, offrendogli un'ulteriore possibilità per ravvedersi, convertirsi e credere. [...] Se Dio si fermasse alla giustizia cesserebbe di essere Dio, sarebbe come tutti gli uomini che invocano il rispetto della legge. La giustizia da sola non basta, e l'esperienza insegna che appellarsi solo ad essa rischia di distruggerla. Per questo Dio va oltre la giustizia con la misericordia e il perdono. Ciò non significa svalutare la giustizia o renderla superflua, al contrario. Chi sbaglia dovrà scontare la pena. Solo che questo non è il fine, ma l'inizio della conversione, perché si sperimenta la tenerezza del perdono. Dio non rifiuta la giustizia. Egli la ingloba e supera in un evento superiore dove si sperimenta l'amore che è a fondamento di una vera giustizia. Dobbiamo prestare molta attenzione a quanto scrive Paolo per non cadere nello stesso errore che l'Apostolo rimproverava ai Giudei suoi contemporanei: "Ignorando la giustizia di Dio e cercando di stabilire la propria, non si sono sottomessi alla giustizia di Dio. Ora, il termine della Legge è Cristo, perché la giustizia sia data a chiunque crede" (Rm 10,3-4). Questa giustizia di Dio è la misericordia concessa a tutti come grazia in forza della morte e risurrezione di Gesù Cristo. La Croce di Cristo, dunque, è il giudizio di Dio su tutti noi e sul mondo, perché ci offre la certezza dell'amore e della vita nuova ${ }^{101}$.

Como se apreende do quanto ensinado pelo Papa Francisco, a Justiça, na Igreja, é indispensável e necessária, mas ela é o passo primeiro para se atingir a plenitude expressada na Misericórdia. Assim, não é possível compreender a Justiça Eclesial sem que seja essencialmente expressão da Misericórdia de Deus, assumida por todos. A Justiça deverá, todavia, ir à frente, conduzindo a todos no caminho da verdade, para que melhor se possa tornar concreta a Misericórdia.

101 FRANCISCUS, 2015, p. 414-416. 


\section{Conclusão}

À guisa de conclusão, é imperioso evocar o Cân. 1752 do Código de Direito Canônico de 1983, que, sintetizando todo o Código, proclama a salvação das almas como a lei suprema da Igreja: "salus animarum suprema lex est." A Justiça de Deus é a sua Misericórdia; e na sua Misericórdia, temos a salvação. A salvação é a missão primeira da Igreja, é a sua lei maior. "A Justiça é inseparável da Caridade, é-lhe intrínseca. A justiça é o primeiro caminho da caridade, ou como chegou a dizer Paulo VI, 'a medida mínima' dela"102.

E, portanto, a Justiça e a Misericórdia darão razão de ser à Caridade Pastoral. A Justiça na Igreja será sempre pastoral. Não pode haver uma ação pastoral autêntica, como expressão concreta e atualização da missão de Cristo, Bom Pastor, que não seja expressão da Justiça em todas as suas manifestações concretas.

\section{BIBLIOGRAFIA}

\section{Fontes}

CODEX Iuris Canonici. Acta Apostolicae Sedis, Vaticana, v. LXXV, pars II, 1983.

CONCÍLIO VATICANO II. Constituição Pastoral Gaudium et Spes. In: VIER, F. (Coord.). Compêndio do Vaticano II: constituições, decretos, declarações. 23. ed. Petrópolis: Vozes, 1994.

CONCILIUM OECUMENICUM VATICANUM II. Constitutio Pasroralis Gaudium et Spes. Acta Apostolicae Sedis, Vaticana, v. LVIII, n. 15, 7 dec. 1966.

CONFERÊNCIA GERAL DO EPISCOPADO LATINOAMERICANO. Evangelização no presente e no futuro da Amé-

102 GOMES, D. Justiça e Misericórdia: a Igreja realmente precisa de um direito canônico? São Paulo: Ecclesiae, 2016. p. 89. 
rica-Latina: conclusões da III Conferência Geral do Episcopado Latino-Americano. 5 ed. São Paulo: Paulinas, 1983.

DECRETUM Magistri Gratiani. London: Forgotten Book, 2018.

DIGESTA Iustiniani Augusti. Mediolani: Formis Societatis Librariae, 1960.

FRANCISCUS. Bulla de Iubilaeo Extraordinario indicendo Misericordiae Vultus. Acta Apostolicae Sedis, Vaticana, v. CVII, n. 5, 1 maii 2015.

GIOVANNI PAOLO II. Non c'è pace senza giustizia, non c'è giustizia senza perdono: messaggio di Sua Santità Giovanni Paolo II per la Giornata Mondiale della Pace. L'Osservatore Romano, Vaticano, CXLI, n. 284, 12 dic. 2001.

IOANNES PAULUS II. Littera Encyclica Dives in misericordia. Acta Apostolicae Sedis, Vaticana, v. LXXII, n. 9, 29 dec. 1980.

LEO MAGNUS. Sermo XCV: sive homilia de gradibus ascensionis ad beatitudinem. In: MIGNE, J. P. (Cur.). Patrologiae cursus completus. Paris: 1844-1866. Series Latina, tom. LIV.

PAOLO VI. Discorso per la Giornata dello Sviluppo: l'amore di Cristo principio di rinnovamento morale e sociale. In: INSEGNAMENTI di Paolo VI. Vaticano: Typografia Poliglotta Vaticana, 1964. vol. VI.

PAULUS VI. Adhortatio Apostolica Evangelii nuntiandi. Acta Apostolicae Sedis, Vaticana, v. LXVIII, n. 1, 31 ian. 1976.

PAULUS VI. Allocutiones: VII ad Praelatos Auditores et Officiales Tribunalis Sacrae Romanae Rotae, a Beatissimo Patre novo litibus iudicandis ineunte anno coram admissos. Acta Apostolicae Sedis, Vaticana, v. LXV, n. 2, 28 feb. 1973.

SINODO DEI VESCOVI. De iustitia in mundo. In: LORA, E. (Cur.). Enchiridion Vaticanum. 13. ed. Bologna: EDB, 1985.

SYNODUS EPISCOPORUM. De iustitia in mundo. Acta Apostolicae Sedis, Vaticana, v. LXIII, n. 12, 22 dec. 1971. 
THOMAS AQUINAS, Summa Theologiae. Trad. A. Corrêa. 2. ed. Porto Alegre: Sulina, 1980.

\section{Autores}

ALFARO, J. Teologia della giustizia. Roma: Paoline, 1973.

ARISTOTELES. Etica Nicomaquea. In: OBRAS. Madrid: Aguilar, 1964.

ARROBA CONDE, M. J. Diritto processuale canonico. 6 ed. Roma: Ediurcla, 2012.

BERTONE, T. La Chiesa e l'impegno per la giustizia. Legalità, giustizia, moralità. In: LA GUISTIZIA nella Chiesa: fondamento divino e cultura processualistica moderna. Vaticano: Libreria Editrice Vaticana, 1997.

BONARA, A. Giustizia. In: ROSSANO, P.; RAVASI, G.; GIRLANDA, A. (Edd.). Nuovo Dizionario di Teologia Biblica. 3. ed. Milano: San Paolo, 1989.

CAMPANINI, G. Giustizia. In: PACOMIO, L. (Coord.). Dizionario Teologico Interdisciplinare. Torino: Marietti, 1977. v. 2.

CICÉRON. Le Devoir. Étab. et trad. M. Testard. 2. ed. Paris, 1974.

COZZOLI, M. Il settimo comandamento. In: FISICHELLA, R. (Cur.). Commento Teologico al Catechismo della Chiesa Cattolica. Casalle Monferrato: PIEMME, 1993.

COZZOLI, M. Virtù Sociale. In: GOFFI, T.; PIANNA, G. (Cur.). Corso di Morale. 2 ed. Brescia: Queriniana, 2002. v. 4, Koinonia: etica della vita sociale.

D’AGOSTINO, F. Il diritto come problema teologico ed altri saggi di filosofia e teologia del diritto. In: ; VIOLA, F. (Dir.) Recta Ratio: testi e studi di filosofia del diritto. 3. ed. Torino: G. Giappichelli, 1997. 
D’AGOSTINO, F. Filosofia del diritto. In: ; VIOLA, F. (Dir.). Recta Ratio: testi e studi di filosofia del diritto. 2. ed. Torino: G. Giappichelli, 1996.

DEL VECCHIO, G. Giustizia. In: AZARA, A.; EULA, E. (Dir.) Novissimo Digesto Italiano. Torino: Torinese, 1961. v. VII.

DEL VECCHIO, G. Giustizia. In: CENTRO DI STUDI FILOSOFICI DI GALLARATE. Enciclopedia Filosofica. Venezia; Roma: Instituto per la Collaborazione Culturale, 1957.

ERRÁZURIZ M., C. J. Il Diritto e la Giustizia nella Chiesa: per una teoria fondamentale del Diritto Canonico. Milano: Giuffrè, 2000 .

ESTRADA, J. A. La Iglesia ¿Institución o carisma? Salamanca: Sigueme, 1984.

GHIRLANDA, G. Il Diritto nella Chiesa: mistero de comunione. In: COMPENDIO di Diritto Ecclesiale. 6 ed. Roma: Gregorian \& Biblical, 2015.

GOMES, D. Justiça e Misericórdia: a Igreja realmente precisa de um direito canônico? São Paulo: Ecclesiae, 2016.

GROCHOLEWSKI, Z. Aspetti teologici dell'attività giudiziaria della Chiesa. Monitor Ecclesiasticus, Roma, 110, 1985.

HAMEL, E. I fondamenti dell'etica cristiana in ordine alla giustizia sociale: fede e giustizia sociale. In: Communio, Milano, 38, 1978.

HÄRING, B. Liberi e Fedeli in Cristo: teologia morale per preti e laici. 2. ed., Roma: San Paolo, 1982. v. III.

JEMOLO, A. C. Giustizia e Diritto. In: Ephemerides Iuris Canonici, 47, 1991.

LENER, S. Giustizia, carità e misericordia: per un'analisi correlativa delle tre idee. La Civiltà Cattolica, Roma, v. 132, n. 2, 1981.

LENER, S. Sulla natura specifica del Diritto Canonico. La Civiltà Cattolica, Roma, v. 133, n. 3, 1982. 
PIVA, P. Misericordia. In: ROSSI, L.; VALSECCHI, A. (Dir.). Dizionario Enciclopedico di Teologia Morale. 7 ed. Milano: Paoline, 1987.

VIEIRA, T. P. O nosso Deus, um Deus Ecológico: por uma compreensão ético-teológica da ecologia. São Paulo: Paulus, 1999. 